\title{
PEMODELAN SISTEM PENDUKUNG KEPUTUSAN \\ PROMOSI JABATAN PADA PERUSAHAAN ASURANSI \\ DENGAN MENGGUNAKANMETODE FUZZY MAMDANI
}

\author{
Arief Andy Soebroto \\ Program Studi Informatika \\ Program Teknologi Informasi dan Ilmu Komunikasi \\ Universitas Brawijaya
}

ariefas@ub.ac.id

\begin{abstract}
Abstrak-Promosi jabatan adalah pengakuan profesionalitas yang diberikan perusahaan kepada pegawai atas kinerjanya. Promosi jabatan dapat meningkatkan kepuasan dan efektifitas kerja pegawai. Peluang promosi jabatan dapat membuat pegawai merasa dihargai, diperhatikan, dibutuhkan dan diakui kemampuan kerjanya oleh perusahaan. Salah satu dampak positif promosi jabatan adalah menghasilkan loyalitas yang tinggi pada perusahaan. Namun dalam memutuskan promosi jabatan dibutuhkan ketepatan optimum dalam pemilihan pegawai yang layak untuk memperolehnya. Faktor-faktor yang mempengaruhi keputusan dalam promosi jabatan harus lebih diperhatikan seperti kriteria lama kerja, kedisiplinan, kerjasama, prestasi kerja dan penampilan. Model penelitian yang diusulkan adalah sistem pendukung keputusan promosi jabatan pada perusahaan asuransi menggunakan metode fuzzy mamdani. Metode tersebut digunakan untuk proses perhitungan nilai dari setiap kriteria dalam menentukan preferensi. Hasil perhitungan tersebut menjadi acuan manager dalam penentuan pegawai mana yang layak diberikan promosi jabatan.
\end{abstract}

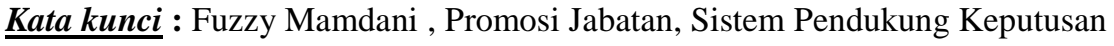

\begin{abstract}
Promotion of professionalism is the recognition given to employees on company performance. Promotion can increase employee job satisfaction and effectiveness. Promotion opportunities can make employees feel valued, cared for, needed and recognized his ability by the company. One of the positive impact of the promotion is to produce a high loyalty to the company. However, in deciding the promotion of optimum accuracy is needed in the selection of employees eligible to get it. Factors that influence the decision of the promotion criteria should be considered as working time, discipline, teamwork, performance and appearance. The proposed research model is a decision support system in the promotion of insurance companies using fuzzy method mamdani. The method used for calculating the value of each criterion in determining preferences. The results of these calculations a reference manager in determining which employees are given proper promotion.
\end{abstract}

Keywords : Decision support systems, Promotion of professionalism, Mamdani Fuzzy.

\section{PENDAHULUAN}

Perusahaan asuransi jiwa berkembang pesat sejalan dengan perkembangan ekonomi dan budaya bangsa Indonesia. Semakin banyak pula pekerja yang turut membantu perkembangan dari perusahaan asuransi itu sendiri.Promosi jabatan merupakan balas jasa yang diberikan perusahaan kepada pegawai atas kinerjanya. Adanya Promosi jabatan dapat meningkatkan kepuasan dan efektifitas kerja pegawai. Selain itu, adanya peluang promosi jabatan dapat membuat pegawai merasa dihargai, diperhatikan, dibutuhkan dan diakui kemampuan kerjanya oleh manajemen perusahaan sehingga mereka akan menghasilkan kinerja serta loyalitas tinggi pada perusahaan. Promosi dalam perusahaan dapat dilakukan karena senioritas dan prestasi kerja seorang pegawai.

Pimpinanperusahaanselaku pengambil keputusan akan sulit menentukan siapa pegawai yang layak untuk diberi promosi jabatan. Kesulitan ini tentunya terkait dengan faktor subyektifitas dan kualitatif sehinggan unsur ketidakpastian untuk menentukan keputusan dapat berpengaruh dalam pengambilan keputusan.

Sistem pendukung keputusan dapat membantu dalam menentukan pegawai yang layak untuk diberi promosi jabatan [6]. Beberapa metode sistem pendukung keputusan dalam hal ketidakpastian ada beberapa yaitu Certainty

Factor [2], Bayesian Rule [3], Dempster-Shafer Theory [4] dan Fuzzy Inference [5].Pada penelitian ini diusulkan pemodelan sistem pendukung keputusan promosi jabatan menggunakan metode fuzzy mamdani. Kriteria promosi jabatan yang dipergunakan adalah Lama Kerja, Kedisiplinan, Prestasi Kerja, Kerjasama, dan Penampilan.

\section{METODOLOGI}

Tahapan penelitian dalam pemodelan tesebut dapat ditunjukkan dalam arsitektur Sistem Pendukung Keputusan seperti yang ditunjukkan dalam gambar 1 . 
Data pegawai perusahaan asuransi yang dipergunakan meliputi 5 kriteria yaitu Lama Kerja, Kedisiplinan, Prestasi Kerja, Kerjasama, dan Penampilan seperti ditunjukkan dalam Tabel 1. Managemen data meliputi penyiapan data model pegawai, preposesing data dan penyiapan basis data pegawai yang nantinya dipergunakan dalam proses komputasi.

Hasil preprosesing data 5 kriteria tersebut memiliki beberapa katagori yaitu ditunjukkan dalam tabel 2 sampai dengan tabel 6. Data yang ditunjukkan dalam tabel tersebut merupakan hasil konsultasi dan pembentukan aturan

Setelah data dan aturan dibuat dalam basis pengetahuan makaselanjutya pembentukan model inferensi. Model inferensi yang digunakan adalah fuzzy mamdani.Metode Mamdani sering juga dikenal dengan nama Metode MaxMin. Metode ini diperkenalkan oleh Ebrahim Mamdani pada tahun 1975. Tahapan metode Fuzzy Mamdani adalah: (1) Pembentukan himpunan fuzzy; (2) Aplikasi fungsi implikasi (aturan); (3) Komposisi aturan; (4) Penegasan (deffuzy) [7]. Hasil preferensi dari Sistem Pendukung Keputusan Promosi Jabatan pada Perusahaan Asuransi menggunakan metode Fuzzy Mamdani adalah Layak dan Tidak Layak.

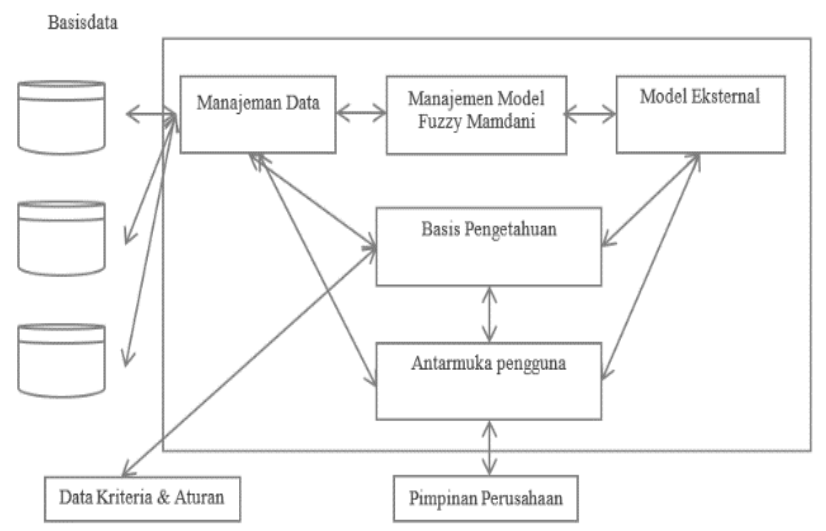

Gambar 1. Arsitektur SPK Promosi Jabatan

Tabel 1. Kriteria Promosi Jabatan

\begin{tabular}{|c|c|}
\hline Kriteria & Keterangan \\
\hline $\mathrm{C}_{1}$ & Lama Kerja \\
\hline $\mathrm{C}_{2}$ & Kedisiplinan \\
\hline $\mathrm{C}_{3}$ & Prestasi Kerja \\
\hline $\mathrm{C}_{4}$ & Kerja Sama \\
\hline $\mathrm{C}_{5}$ & Penampilan \\
\hline
\end{tabular}

Tabel 2. Katagori Kriteria Lama Kerja

\begin{tabular}{|l|c|}
\hline Katagori & Masa Kerja (Tahun) \\
\hline Baru & $0-3$ \\
\hline Sedang & $1-5$ \\
\hline Lama & Lebih dari 5 \\
\hline
\end{tabular}

Tabel 3 Katagori Kriteria Kedisiplinan

\begin{tabular}{|l|c|}
\hline \multicolumn{1}{|c|}{ Katagori } & Kehadiran (Hari) \\
\hline Tidak Disiplin & $0-17$ \\
\hline Agak Dispilin & $14-22$ \\
\hline Disiplin & Lebih dari 22 \\
\hline
\end{tabular}

Tabel 4 Katagori Kriteria Prestasi Kerja

\begin{tabular}{|l|c|}
\hline \multicolumn{1}{|c|}{ Katagori } & Aktifitas (Item) \\
\hline Tidak & $0-5$ \\
\hline Sedang & $4-8$ \\
\hline Berprestasi & Lebih dari 8 \\
\hline
\end{tabular}

Tabel 5 Katagori Kriteria Kerjasama

\begin{tabular}{|l|c|}
\hline \multicolumn{1}{|c|}{ Katagori } & Skor \\
\hline Tidak & $0-50$ \\
\hline Kurang & $40-70$ \\
\hline Kooperatif & Lebih dari 80 \\
\hline
\end{tabular}

Tabel 6Katagori Kriteria Penampilan

\begin{tabular}{|c|c|}
\hline Katagori & Skor \\
\hline Tidak Rapi & $0-70$ \\
\hline Rapi & Lebih dari 80 \\
\hline
\end{tabular}

\section{Pembentukan Fungsi Keanggotaan Himpunan Fuzzy}

Berdasarkan data dan aturan yang ditunjukkandalam Tabel 1 sampai dengan Tabel 6 maka fungsi keanggotaan himpunan fuzzy ada 5 kriteria.

a. Lama Kerja

$$
\begin{aligned}
& \mu_{\text {Baru }}(x)=\left\{\begin{array}{cc}
\frac{1}{\frac{a-x}{2}} & 1 \leq x \leq 3 \\
0 & x \geq 3
\end{array}\right. \\
& \mu_{\text {Sedang }}(x)=\left\{\begin{array}{cc}
\frac{x-1}{2} & 1 \leq x \leq 3 \\
\frac{x-5}{-2} & 3 \leq x \leq 5 \\
0 & \text { lainnya }
\end{array}\right. \\
& \mu_{\text {Lama }}(x)=\left\{\begin{array}{cc}
0 & x \leq 3 \\
\frac{x-a}{2} & 3 \leq x \leq 5 \ldots . \\
1 & x \geq 5
\end{array}\right.
\end{aligned}
$$

b. Kedisiplinan

$\mu_{T D}(x)=\left\{\begin{array}{cc}1 & x \leq 14 \\ \frac{17-x}{a} & 14 \leq x \leq 17 \ldots . . \\ 0 & x \geq 17\end{array}\right.$ 


$$
\begin{aligned}
& \mu_{C D}(x)=\left\{\begin{array}{cc}
\frac{x-14}{a} & 14 \leq x \leq 17 \\
\frac{x-22}{-5} & 17 \leq x \leq 22 \ldots \ldots \ldots \ldots . . . \\
0 & \text { lainnya }
\end{array}\right. \\
& \mu_{D}(x)=\left\{\begin{array}{cc}
0 & x \leq 17 \\
\frac{x-17}{5} & 17 \leq x \leq 22 \ldots \ldots \ldots \ldots \ldots . . \\
1 & x \geq 22
\end{array}\right.
\end{aligned}
$$

c. Prestasi Kerja

$$
\begin{aligned}
& \mu_{\text {tidak }}(x)=\left\{\begin{array}{cc}
1 & x \leq 3 \\
\frac{5-x}{2} & 3 \leq x \leq 5 \ldots \ldots \ldots \ldots \ldots . . . . . .17 \\
0 & x \geq 5
\end{array}\right. \\
& \mu_{\text {cukup }}(x)=\left\{\begin{array}{lr}
\frac{x-a}{2} & 3 \leq x \leq 5 \\
\frac{x-9}{-a} & 5 \leq x \leq 8 \\
0 & \text { lainnya }
\end{array}\right. \\
& \mu_{\text {Berprestagi }}(x)=\left\{\begin{array}{cc}
0 & x \leq 5 \\
\frac{x-5}{a} & 5 \leq x \leq 8 . \\
1 & x \geq 8
\end{array}\right.
\end{aligned}
$$

d. Kerjasama

$$
\begin{aligned}
& \mu_{\text {tidak }}(x)=\left\{\begin{array}{cc}
1 & x \leq 25 \\
\frac{50-x}{25} & 25 \leq x \leq 50 \ldots \ldots \ldots \\
0 & x \geq 50
\end{array}\right. \\
& \mu_{\text {Sedang }}(x)=\left\{\begin{array}{cc}
\frac{x-25}{25} & 25 \leq x \leq 50 \\
\frac{x-80}{-30} & 50 \leq x \leq 80 \ldots \ldots \ldots \ldots . . . \\
0 & \text { lainnya }
\end{array}\right. \\
& \mu_{\text {Kaoparatif }}(x)=\left\{\begin{array}{cc}
0 & x \leq 50 \\
\frac{x-50}{30} & 50 \leq x \leq 80 \ldots \ldots \ldots \ldots . . . \\
1 & x \geq 80
\end{array}\right.
\end{aligned}
$$

e. Penampilan

$$
\begin{aligned}
& \mu_{\text {Tidak }}(x)=\left\{\begin{array}{cc}
1 & x \leq 50 \\
\frac{80-x}{a 0} & 50 \leq x \leq 80 \ldots \ldots \\
0 & x \geq 80
\end{array}\right. \\
& \mu_{\text {Rapi }}(x)=\left\{\begin{array}{cc}
0 & x \leq 50 \\
\frac{x-50}{\mathrm{a} 0} & 50 \leq x \leq 80 \ldots \ldots . \\
1 & x \geq 80
\end{array}\right.
\end{aligned}
$$

\section{Aplikasi Fungsi Implikasi}

Pada Metode Mamdani, fungsi implikasi yang digunakan adalah Min.

\section{Komposisi Aturan}

Berdasarkan data dan fungsi keanggotaan himpunan fuzzy maka selanjutnya dapat ditentukan kombinasi aturan yang memungkinkan. Perhitungan dari kombinasi kroteria tersebut yaitu :
Rule $=3 \times 3 \times 3 \times 3 \times 2=162$

Jadi terdapat 162 aturan atau rule yang diantaranya dapat dilihat pada tabel. Kriteria lama kerja memiliki 3 katagori. Kriteria kedisiplinan memiliki 3 katagori. Kriteria prestasi kerja memiliki 3 katagori. Kriteria kerjasama memiliki 3 katagori dan kriteria penampilan memiliki 2 katagori.

\section{Penegasan (defuzzykasi)}

Input dari proses defuzzifikasi adalah suatu himpunan fuzzy yang diperoleh dari komposisi aturan-aturan fuzzy, sedangkan output yang dihasilkan merupakan suatu bilangan pada domain himpunan fuzzy tersebut. Sehingga jika diberikan suatu himpunan fuzzy dalam range tertentu, maka harus dapat diambil suatu nilai crsip tertentu sebagai output seperti terlihat pada gambar berikut.

Ada beberapa metode defuzzifikasi pada komposisi aturan MAMDANI, antara lain:

\section{a. $\quad$ Metode Centroid (Composite Moment)}

Pada metode ini, solusi crisp diperoleh dengan cara mengambil titik pusat $\left(z^{*}\right)$ daerah fuzzy. Secara umum titik persamaan $\mathrm{z}^{*}$ dapat ditentukan dengan persamanaan (1) dan (2):

$$
\begin{aligned}
& z^{*}=\frac{\int_{Z} z_{\mu}(z) d z}{\int_{Z} \mu(z) d z} . \\
& z^{*}=\frac{\sum_{j-1}^{n} z_{j \mu}\left(z_{j}\right)}{\sum_{j=1}^{n} \mu\left(z_{j}\right)}
\end{aligned}
$$

b. Metode Bisektor

Pada metode ini, solusi crisp diperoleh dengan cara mengambil nilai pada domain fuzzy yang memiliki nilai keanggotaan setengah dari jumlah total nilai keanggotaan pada daerah fuzzy. Secara umum solusi crisp ditentukan dengan persamaan (13):

$z_{p}$ sedemikian $h \int_{R_{2}}^{p} \mu(z) d z=\int_{p}^{R_{H_{1}}} \mu(z) d z .$.

\section{c. Metode Mean of Maximum (MOM)}

Pada metode ini, solusi crisp diperoleh dengan cara mengambil nilai rata-rata domainyang memiliki nilai keanggotaan maksimum.

d. Metode Largest of Maximum (LOM)

Pada metode ini, solusi crisp diperoleh dengan cara mengambil nilai terbesar daridomain yang memiliki nilai keanggotaan maksimum.

e. $\quad$ Metode Smallest of Maximum (SOM)

Pada metode ini, solusi crisp diperoleh dengan cara mengambil nilai terkecil daridomain yang memiliki nilai keanggotaan maksimum. 
Tabel 7. Komposisi Aturan

\begin{tabular}{|c|c|c|c|c|c|c|}
\hline $\begin{array}{c}\sum \\
\text { Rule }\end{array}$ & $\begin{array}{c}\text { Lama } \\
\text { Kerja }\end{array}$ & Kedisiplinan & $\begin{array}{c}\text { Prestasi } \\
\text { Kerja }\end{array}$ & Kerjasama & Penampilan & HASIL \\
\hline 2 & Baru & $\begin{array}{c}\text { Tidak } \\
\text { Disiplin }\end{array}$ & $\begin{array}{c}\text { Tidak } \\
\text { Berprestasi }\end{array}$ & $\begin{array}{c}\text { Tidak } \\
\text { Kerjasama }\end{array}$ & Tidak Rapi & $\begin{array}{c}\text { Tidak } \\
\text { Layak }\end{array}$ \\
\hline 49 & Baru & Disiplin & Berprestasi & $\begin{array}{c}\text { Tidak } \\
\text { Kerjasama }\end{array}$ & Rapi & Layak \\
\hline 83 & Sedang & $\begin{array}{c}\text { Cukup } \\
\text { disiplin }\end{array}$ & $\begin{array}{c}\text { Cukup } \\
\text { Berprestasi }\end{array}$ & Kooperatif & Rapi & $\begin{array}{c}\text { Tidak } \\
\text { Layak }\end{array}$ \\
\hline 89 & Sedang & $\begin{array}{c}\text { Cukup } \\
\text { disiplin }\end{array}$ & Berprestasi & Kooperatif & Tidak Rapi & $\begin{array}{c}\text { Tidak } \\
\text { Layak }\end{array}$ \\
\hline 101 & Sedang & Disiplin & $\begin{array}{c}\text { Cukup } \\
\text { Berprestasi }\end{array}$ & Kooperatif & Rapi & Layak \\
\hline 103 & Sedang & Disiplin & Berprestasi & $\begin{array}{c}\text { Tidak } \\
\text { Kerjasama }\end{array}$ & Rapi & Layak \\
\hline 107 & Sedang & Disiplin & Berprestasi & Kooperatif & Rapi & Layak \\
\hline 125 & Lama & $\begin{array}{c}\text { Tidak } \\
\text { Disiplin }\end{array}$ & Berprestasi & Kerjasama & Rapi & Layak \\
\hline 158 & Lama & Disiplin & Berprestasi & $\begin{array}{c}\text { Tidak } \\
\text { Kerjasama }\end{array}$ & Tidak Rapi & Layak \\
\hline
\end{tabular}

II. HASIL DAN PEMBAHASAN

Jika terdapat kasus seorang pegawai dengan data-data kriteria dibawah ini :

$\begin{array}{lll}\text { - } & \text { Lama Kerja } & : 3 \text { tahun } \\ \text { - } & \text { Kedisiplinan } & : 20 \text { hari masuk kerja } \\ \text { - } & \text { Prestasi Kerja } \quad: 7 \text { (skala 1-10) } \\ \text { - } & \text { Kerjasama: 80 (skala 1-100) } \\ \text { - } & \text { Penampilan } \quad: 85 \text { (skala 1-100) }\end{array}$

Mengacu pada fungsi keanggotaan kelompok masingmasing diperoleh nilai keanggotaan masing-masing data yaitu :

Lama Kerja : 3 tahun

Berdasarkan persamaan (1), (2) dan (3) diperoleh:

$\mu_{\text {Baru }}(3)=\frac{3-x}{2}=0$

$\mu_{\text {Sedang }}(3)=\frac{x-1}{2}=1$

$$
\mu_{\text {Lama }}(3)=\frac{x-3}{2}=0
$$

- Kedisiplinan : 20 hari masuk kerja

Berdasarkan persamaan (4), (5) dan (6) diperoleh:

$\mu_{T D}(20)=0$

$\mu_{C D}(20)=\frac{x-22}{-5}=0,4$

$\mu_{\text {Disiplin }}(20)=\frac{x-17}{5}=0,6$

Prestasi Kerja : 7 (skala 1-10)

Berdasarkan persamaan (7), (8) dan (9) diperoleh:

$\mu_{\text {Tidak }}(7)=0$

$\mu_{\text {euhup }}(7)=\frac{x-8}{-3}=0,333$

$\mu_{\text {Eerprestasi }}(7)=\frac{x-5}{3}=0,667$

- Kerjasama: 80 (skala 1-100)

- Berdasarkan persamaan (10), (11) dan (12) diperoleh:

$\mu_{\text {Tidak }}(80)=0$

$\mu_{\text {sedang }}(80)=\frac{x-80}{-30}=0$

$\mu_{\text {kooperatif }}(80)=\frac{x-50}{30}=1$

Penampilan : 85 (skala 1-100)
- Berdasarkan persamaan (13) dan (14) diperoleh:

$$
\begin{aligned}
& \mu_{\text {tidak }}(85)=0 \\
& \mu_{\text {rapi }}(85)=1
\end{aligned}
$$

Berdasarkan nilai keanggotaan tersebut, maka aturan predikat untuk penilaian kriteria umum yang ada antara lain :

a. Jika Lama Kerja adalah Sedang AND Kedisiplinan adalah Cukup disiplin AND Prestasi Kerja adalah Cukup Berprestasi AND Kerjasama adalah Kooperatif AND Penampilan adalah Rapi THEN HASIL adalah Tidak Layak

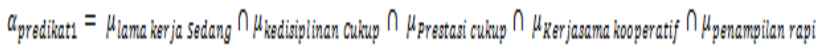

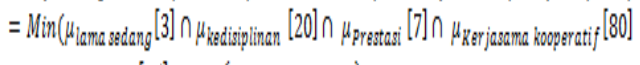

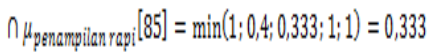

b. Jika Lama Kerja adalah Sedang AND Kedisiplinan adalah Disiplin AND Prestasi Kerja adalah Berprestasi AND Kerjasama adalah Kooperatif AND Penampilan adalah Rapi THEN HASIL adalah Layak

$\alpha_{\text {predikat2 }}=\mu_{\text {lama kerja sedang }}$

$\cap \mu_{\text {kedigiplinan Disiplin }} \cap \mu_{\text {Prestasi Berprestasi }} \cap \mu_{\text {Kerjasama kooperatif }} \cap \mu_{\text {penampilan rapi }}$

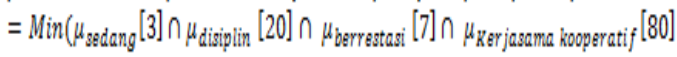
$\cap \mu_{\text {penampilian rapi }}[85]=\min (1 ; 0,6 ; 0,667 ; 1 ; 1)=0,6$

c. Jika Lama Kerja adalah Sedang AND Kedisiplinan adalah Cukup disiplin AND Prestasi Kerja adalah Berprestasi AND Kerjasama adalah Kooperatif AND Penampilan adalah Rapi THEN HASIL adalah Tidak Layak

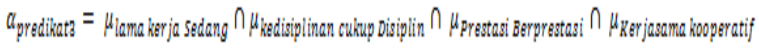

$$
\begin{aligned}
& \text { ก } \mu_{\text {prnangilan rapi }}
\end{aligned}
$$

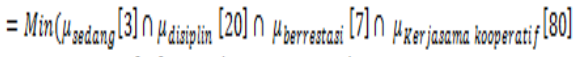

$$
\begin{aligned}
& n \mu_{\text {penangilans rapi }}[85]=\min (1 ; 0,0 ; 0,067 ; 1 ; 1)=0,4
\end{aligned}
$$

d. Jika Lama Kerja adalah Sedang AND Kedisiplinan adalah Disiplin AND Prestasi Kerja adalah Cukup Berprestasi AND Kerjasama adalah Kooperatif AND Penampilan adalah Rapi THEN HASIL adalah Layak

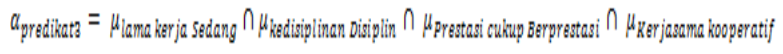

ก $\mu_{\text {ponangilan rapi }}$

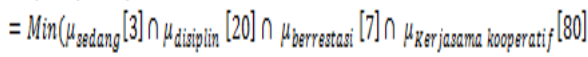

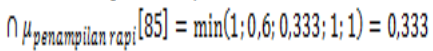

Hasil penilaian kelayakan promosi jabatan terdiri dari 2 himpunan fuzzy, yaitu: layak dan tidak layak.

$$
\begin{aligned}
& \mu_{\text {Tidak layak }}(x)=\left\{\begin{array}{cc}
1 & x \leq 50 \\
\frac{80-x}{90} & 50 \leq x \leq 80 \ldots . \\
0 & x \geq 80
\end{array}\right. \\
& \mu_{\text {Layak }}(x)=\left\{\begin{array}{cc}
0 & x \leq 50 \\
\frac{x-50}{\mathrm{a} 0} & 50 \leq x \leq 80 \ldots \ldots \ldots . \\
1 & x \geq 80
\end{array}\right.
\end{aligned}
$$


Komposisi antar aturan

Dari hasil aplikasi fungsi implikasi dari tiap aturan, digunakan metode MAX untuk melakukan komposisi antar semua aturan.

TIDAK LAYAK $=\max (0,333 ; 0,4)=0,4$

LAYAK $=\max (0,6 ; 0,333)=0,6$

Daerah hasil kita bagi menjadi 3 bagian, yaitu A1, A2, dan A3. Sekarang kita cari nilai a1 dan a2 berdasarkan persamaan (4-16):

$(\mathrm{a} 1-50) / 30=0,4--->\mathrm{a} 1=62$

$(\mathrm{a} 2-50) / 30=0,6-->\mathrm{a} 2=68$

Dengan demikian, fungsi keanggotaan untuk hasil komposisi ini adalah:

$\mu_{z}(z)=\left\{\begin{array}{cc}0,4 & z \leq 62 \\ \frac{z-50}{a 0} & 62 \leq z \leq 68 . \\ 0,6 & z \geq 68\end{array}\right.$

1. Defuzzy (penegasan)

Metode penegasan yang akan kita gunakan adalah metode centroid. Untuk itu, pertama kita hitung dulu momen untuk setiap daerah.

$$
\begin{aligned}
& M 1=\int_{0}^{62}(0,4) z d z=0,\left.2 z^{2}\right|_{0} ^{62}=768,8 \\
& M 2=\int_{62}^{60} \frac{(z-50)}{30} z d z=195,6 \\
& M 3=\int_{60}^{100}(0,6) z d z=1612,8
\end{aligned}
$$

Kemudian kita hitung luas setiap daerah:

$$
\begin{array}{ll}
\text { A1 } & =\mathrm{a} 1 * \mu_{\text {Tidak layak }} \\
& =62 * 0,4=24,8 \\
\text { A2 } \quad= & \frac{\left(\mu_{\text {layak }}+\mu_{\text {Tidak layak }}\right) *(\mathrm{a} 2-\mathrm{a} 1)}{2} \\
& =\frac{(0,4+0,6) *(68-62)}{2}=3 \\
\text { A3 } \quad & (100-\mathrm{a} 2) * \mu_{\text {layak }} \\
& =(100-68) * 0,6=19,2
\end{array}
$$

Titik pusat dapat diperoleh dari:

$$
\begin{aligned}
Z \quad & =\frac{M 1+M 2+M 3}{A 1+A 2+A 3} \\
& =\frac{768,8+195,6+1612,8}{24,8+3+19,2} \\
& =\frac{2577,2}{47}=54,834
\end{aligned}
$$

Keputusan pembatas $=$ Max (derajat pembatas kei...n * nilai titik pusat $(\mathrm{z})$ )

- Pembatas tidak layak $($ Pem1 $)=0,4 * 54,834=$ 21,9336

- Pembatas layak $($ Pem2) $=0,6 * 54,834=32,9004$

Keputusan pembatas $=\operatorname{Max}($ Pem1 $;$ Pem2 $)=$ Max $(21,9336 ; 32,9004)=32,9004$

Jadi keputusannya adalah Pem2 yaitu Layak.
Dari hasil pengujian terhadap 10 data sampel maka diperoleh hasil pengujian dengan akurasi 2/10 x $100 \%$ $=80 \%$.

Tabel 8. Hasil Pengujian

\begin{tabular}{|c|c|c|c|c|}
\hline Data & Manual & SPK FM & Benar & Salah \\
\hline 1 & Layak & Layak & 1 & 0 \\
\hline 2 & Layak & Layak & 1 & 0 \\
\hline 3 & $\begin{array}{c}\text { Tidak } \\
\text { Layak }\end{array}$ & Tidak Layak & 1 & 0 \\
\hline 4 & Layak & Tidak Layak & 0 & 1 \\
\hline 5 & $\begin{array}{c}\text { Tidak } \\
\text { Layak }\end{array}$ & Tidak Layak & 1 & 0 \\
\hline 6 & $\begin{array}{c}\text { Tidak } \\
\text { Layak }\end{array}$ & Layak & 0 & 1 \\
\hline 7 & Layak & Layak & 1 & 0 \\
\hline 8 & Layak & Layak & 1 & 0 \\
\hline 9 & $\begin{array}{c}\text { Tidak } \\
\text { Layak }\end{array}$ & Tidak Layak & 1 & 0 \\
\hline 10 & Layak & Layak & 1 & 0 \\
\hline
\end{tabular}

\section{KESIMPULAN}

Berdasarkan hasil pengujian maka dapat disimpulkan pemodelan sistem pendukung keputusan promosi jabatan diperoleh akurasi sebesar $80 \%$. Pengembangan metode sebagai pembanding dapat dilakukan untuk mencermati kualitas hasil uji akurasi.

\section{DAFTAR PUSTAKA}

[1] Hasibuan, M.S.P., Manajemen Sumber Daya Manusia, Edisi Revisi, PT Bumi Aksara, Jakarta, 2002.

[2] Cahyo, Budi Saputro, Rosa Delima dan Joko Purwadi. "Sistem Diagnosa Penyakit Diabetes Mellitus Menggunakan Metode Certainty Factor". Open Journal - Jurnal Informatika Unversitas Kristen Duta Wacana Vol 7 No. 1 Tahun 2011.

[3] Hardika Pratama, Angga, Arief Andy Soebroto dan Rekyan Regasari Mardi Putri. "Aplikasi Sistem Pakar Untuk Identifikasi Hama Dan Penyakit Tanaman Tebu Dengan Metode Naïve Bayes Berbasis Web" Repositori Jurnal Mahasiswa PTIIK UB, Vol 3 No. 6 Tahun 2014, ISBN : 3-I-2014-06.

[4] Dewi Prihastuti, Mustika, Arief Andy Soebroto dan Rekyan Regasari Mardi Putri. "Aplikasi Sistem Pakar Untuk Pendeteksian Dan Penanganan Dini Pada Penyakit Sapi Dengan Metode DempsterShafer Berbasis Web" Repositori Jurnal Mahasiswa PTIIK UB, Vol 3 No. 6 Tahun 2014, ISBN : 3-I2014-06. 
[5] Mayasari, Fauziah, Arief Andy Soebroto dan Rekyan Regasari Mardi Putri. " Sistem Pendukung Keputusan Seleksi Beasiswa PPA dan BBM Menggunakan Metode Fuzzy AHP" Repositori Jurnal Mahasiswa PTIIK UB, Vol 1 No. 8 Tahun 2013, ISBN : 3-I-2014-06.

[6] E. Mamdani and S. Assilian, "An experiment in linguistic synthesis with a fuzzy logic controller,'International Journal of Man-Machine Studies, Vol. 7, pp. 1 - 13, 1975.
[7] Kusuma, Dewi, Hari Purnomo. "Aplikasi Logika Fuzzy untuk Pendukung Keputusan”, Edisi Ke-2 Penerbit Graha Ilmu, 2010. 